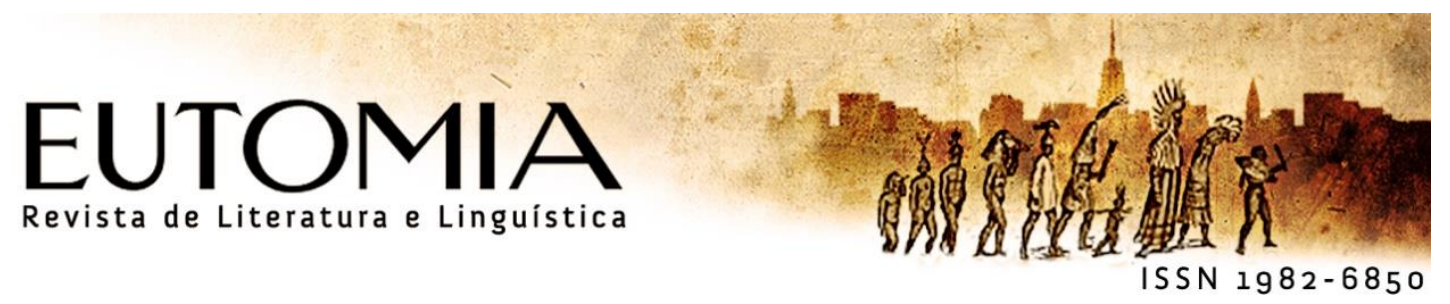

\title{
Iluminismo e práxis: redescobrindo práticas pouco visíveis
}

\author{
Eduardo Guerreiro Brito Losso' (UFRJ)
}

\begin{abstract}
Resumo:
Se fôssemos encarar a velha questão "O que é o esclarecimento" hoje, com a pretensão de responder ou não, não escaparíamos do exercício habitual de separar o que, no lluminismo, foi ultrapassado ou derrotado, e o que é não só atual, mas inevitavelmente necessário para qualquer esforço em prol da liberdade. Minha contribuição será, neste artigo, de questionar, de certo modo, a importância demasiada dada a um tipo de teoria da práxis que advém precisamente do séc. XVIII - privilegiando a ação política e balanço de conjunturas globais - e o esquecimento de outros tipos de prática menos visiveis. Pretendo buscar ampliar essa noção com outras esferas de ação micropolíticas, que desenvolvem a prática de si. Ainda que se encontre uma tendência prometedora para valorizá-la, o campo da prática de si permanece indevidamente menosprezado e carece de mais reflexão.
\end{abstract}

Palavras-chave: Iluminismo, teoria, práxis, liberdade, ascese

\begin{abstract}
:
If we were to face the old question "What is Enlightenment" today, with the pretension of answering it or not, we would not escape the usual exercise of separating what in the Enlightenment has been overcome or defeated, and what is current and inevitably necessary for any effort for freedom. My contribution will be, in this paper, to question, in a way, the exceeding importance given to a type of theory of praxis that comes precisely from the $18^{\text {th }}$ century - privileging the political action and balance of global conjunctures - and the neglect of other less visible types of practice. I intend to expand this notion with other micropolitical spheres of action that develop the practice of self. Although there is a promising tendency to value it, the field of practice of self remains unduly depreciated and need further reflection.
\end{abstract}

Keywords: Enlightenment, theory, praxis, freedom, asceticism 
Se fôssemos encarar a velha questão "O que é o esclarecimento" hoje, com a pretensão de responder ou não, não escaparíamos do exercício habitual de separar o que, no lluminismo, foi ultrapassado ou derrotado, e o que é não só atual, mas inevitavelmente necessário para qualquer esforço em prol da liberdade. Cada corrente política e filosófica vai tomar sua posição interpretativa e atualizar a sua agenda, ao narrar o percurso percorrido do séc. XVIII até hoje e fornecer a sua leitura dos conflitos atuais. Nesse debate interminável, sempre aparecem visões globais e locais da conjuntura contemporânea, faz-se o balanço das lutas sociais, suas conquistas e fracassos, e as possibilidades dos novos meios disponíveis de teoria e práxis.

Minha contribuição será, neste texto, de questionar, de certo modo, a importância dada a um tipo de teoria e práxis, que advém precisamente do séc. XVIII - a ação política e o balanço de conjunturas globais -, e esquecer outros tipos de prática menos visíveis. Pretendo buscar ampliar essa noção com outras esferas de ação e, ainda que se encontre uma tendência teórica de sensibilização nesse sentido, elas se mantêm indevidamente menosprezadas e carecem de mais reflexão.

Em todo o movimento iluminista e, especialmente, no famoso artigo de Kant, a transformação do espírito está intrinsecamente ligada a um ideal de reforma social. A saída da menoridade (Unmündigkeit) não se separa de uma inserção do sujeito no "uso público da razão" (KANT, 1974, p. 104-105). O iluminista acredita no fato de que a política é o lugar privilegiado de qualquer progresso moral, e parece que não só não se pode dissociar liberdade de pensamento de exposição pública de ideias próprias com vistas à mudança da organização social, a ser feita de forma racional, como não se pode até dissociar autonomia de política, em última instância.

É compreensível que tenham pensado assim. Aquele era o momento de enfrentar monarcas tiranos e censuras religiosas, aquele era o tempo kairótico de pressionar o poder a ser racional, a incluir filósofos e cientistas nas decisões majoritárias e defender a necessidade de uma educação para todos. Esse era o modo mais eficaz de libertar o sujeito da tutela dos outros, inaugurar um espaço próprio de reflexão e juízo e, finalmente, educando a população, tornar possível um Estado justo. Em outras palavras: a política pública, irrestrita, regulada pela razão, estava sendo descoberta, e a esperança em seu potencial devia mesmo ser ilimitada. 
Logo, o lluminismo investiu todas as suas forças em liberdade de pensamento e juízo, debate público e reforma social.

Rapidamente se comprovou as dificuldades desse empreendimento. Os iluministas trabalharam na reunião, progressão, organização e divulgação dos saberes na forma de enciclopédia e, para o debate público, depositaram suas expectativas na expansão e liberalização da imprensa. E, em lugar da reforma social, adveio a revolução francesa e a ascensão da burguesia. A ciência passou a servir ao mercado e à diferença de classe; a razão se instrumentalizou e foi perdendo de vista seus fins mais nobres; a imprensa foi tomada pelas ideologias dominantes e cada vez mais serviu de instrumento de manipulação da opinião pública. A esperança no debate público, ao longo do séc. XIX, deu lugar à explícita luta de classes, e a filosofia marxiana se deu conta de que não adiantava interpretar, nem somente participar de um debate amigável, mas lutar numa guerra atroz e sem fim para transformar o mundo. Sua influência levou a novas ditaduras de esquerda, opostas a novas ditaduras de direita, e o ideal iluminista passou muito longe de ambos. Enfim, Adorno e Horkheimer perceberam que o esclarecimento era um fenômeno bem mais amplo que o iluminismo oitocentista, em que mito e razão sempre estiveram imbricados e, com a racionalidade técnica, positivista, e a atração irresistível da indústria cultural, a razão ficou cega, virou mero meio para fins de dominação e regrediu às forças inegociáveis do mito.

Sabe-se que todo esse fracasso motivou Adorno a recuar diante das pretensões marxistas de transformar o mundo. Enquanto Lukács ainda confiava no proletariado como agente e consciência privilegiada da história, Adorno observou que o efeito conjunto da cultura de massa, da burocracia e da tecnocracia impede os próprios sujeitos de se constituírem, hipótese que os iluministas sequer imaginavam que se pudesse ocorrer. Do mesmo modo, a filosofia e as ciências humanas nascentes foram descobrindo que a razão, enquanto dominadora da natureza externa e interna, desconsidera todo um universo de dimensões psíquicas, estéticas e sociais às quais ela não dá conta, que são muito maiores do que se supunha, e que ela não deve ter a pretensão de se assenhorar, mas que deve procurar entender segundo suas possibilidades e limites, e isso é, de fato, uma tarefa que complexificou todo o saber do século XX. 
Por isso que Adorno apostou na experiência estética: "a arte é a crítica da práxis enquanto não-liberdade" (Insofern ist Kunst Kritik von Praxis als Unfreiheit) (ADORNO, 1995, p. 206; ADORNO, 1977, p. 762). Esta tem a capacidade de expressar os elementos recalcados da sociedade, aquilo que não se permite comunicar, e expressar os conflitos sociais da forma mais indireta possível, dentro das sutilezas das operações formais. Educar para a emancipação é, então, mobilizar uma razão crítica direcionada a fins, uma reflexão em torno dos limites da racionalidade, diante de todo um inconsciente povoado de pulsões, e uma experiência estética que ocupe a distância entre sujeito e natureza.

Tudo isso é bem sabido. O que eu gostaria de assinalar é que Adorno, sem deixar de cuidar de toda uma intervenção pública, na universidade e nas rádios de sua época, percebeu que era preciso insistir no papel determinante do tempo solitário, isto é, do que o indivíduo pode fazer por si mesmo, além de descobrir a sua liberdade de pensar e julgar, ou melhor, como fazer amplo uso dessa liberdade. Toda a sua discordância de movimentos políticos e estudantis ocorreu porque ele não acreditava que debates em torno de grandes acontecimentos públicos, visando uma práxis imediata, pudesse surtir muito efeito. Antes disso, para enfrentar todo o aparato midiático de imposição de formas de narrar e interpretar a realidade, bem como modos de agir, seria preciso que o sujeito desenvolvesse mais as possibilidades de sua experiência - é do que o poeta se incumbe, quando se entrega ao "quimérico anseio da linguagem pelo impossível" (die schimärische Sehnsucht der Sprache nach dem Unmöglichen) (ADORNO, 2003, p. 88; ADORNO, 1974, p. 67). Assim, a arte é mais do que uma forma de ocupar o tempo livre com bons livros, mais do que um distintivo social: é uma oficina de autotransformação. O distanciamento da realidade e do contexto, feito para fruir o objeto estético, não é um modo elitista de separar arte de realidade, é uma forma de garantir tanto o distanciamento crítico quanto o espaço de elaboração do sujeito; e a recusa modernista dessa distância, sua "práxis vital" (BÜRGER, 2008, p. 106), só pretende radicalizar tal espaço. A indústria cultural cada vez mais retira do público o gosto por esse tipo de ocupação. Ela, ao facilitar o trabalho da percepção, impede que as pessoas se tornem aptas a exercitá-la.

Curiosamente, por outro lado, todo o movimento das primeiras vanguardas, dos beatniks, dos situacionistas e, enfim, da contracultura (que combinou ideais de vanguarda e 
cultura de massa), tinha como projeto abrir as "portas da Muralha" (HUXLEY, 1966, p. 38-39). Independentemente das discordâncias entre a teoria crítica e esses movimentos, houve um desejo comum de adentrar nessas regiões "para além da razão", no âmbito pessoal e comunitário, com grandes consequências políticas, buscando criar e ocupar novos espaços, concretos e mentais, de atuação artística experimental. Nesse sentido, se se perguntar o que é o esclarecimento dentro desse âmbito, poder-se-ia responder que é desenvolver um tipo de razão limítrofe, digamos assim: trabalhar em prol de uma experiência para fora da razão sem dispensá-la. Para sair da voracidade dominadora da natureza perpetrada pelo esclarecimento, com vistas à autoconservação, é preciso enfrentar aquilo que apavora: o desconhecido. E o desconhecido é tão fascinante quanto perigoso.

"O que eu temo é o que me atrai", cita de um poeta desconhecido Rudolf Otto (OTTO, 2007, p. 68; TÜRCKE, 2008, p. 242). Esse princípio da religião vale também para os tempos em que a juventude pós-moderna descobriu as drogas, e vale ainda mais para os nossos tempos de tecnologia digital. Quanto mais as "máquinas de imagem" se apoderam do aparelho perceptivo, mais embotam a capacidade de atenção e impõem uma sorte de regime feito de altas doses de distração concentrada, segundo Christoph Türcke. A busca pela expansão da consciência pode muito bem regredi-la; na maioria das vezes, especialmente sem o uso da razão crítica, é o que ocorre. Por isso Adorno apostou na concentração em sutilezas formais das obras modernistas; por isso Türcke aposta numa retomada pedagógica de rituais primitivos, antigos e modernos, de modo a resgatar a habilidade de se concentrar por meio de exercícios de retenção que revertam o dano do excesso de estímulos audiovisuais (TÜRCKE, 2016, p. 8586; TÜRCKE, 2012, p. 77-78).

No artigo de 1984 chamado What Is Enlightenment?, Foucault destaca em Kant que a Aufklärung é, em primeiro lugar, uma atitude de modernidade, um modo de pensar como cada um é responsável pela saída da menoridade no presente (FOUCAULT, 2008, p. 337-340). Mas não bastou a Foucault o exemplo de Kant. Em seguida, ele mostra como a modernidade de Baudelaire pratica uma "extrema atenção para com o real" (FOUCAULT, 2008, p. 344), sem menosprezar o presente nem simplesmente aceitá-lo; o poeta francês respeita o real para o violar, alcançando uma transfiguração, em que o poeta inventa a si mesmo. Foucault não cita a 
passagem de Kant em que uma ideia bem semelhante aparece: "Por isso são muito poucos aqueles que conseguiram, pela transformação do próprio espírito, emergir da menoridade e empreender então uma marcha segura" (KANT, 1974, p. 102). De qualquer modo, o dandismo de Baudelaire fornece uma dimensão mais abrangente para entender que tipo de atividade corresponderia ao "cultivo (Bearbeitung) do espírito", se ele não se dá somente com o uso público da razão. Foucault, leitor de Baudelaire, propõe desenvolver novas capacidades individuais. Elas só aparecem quando a atenção ao real abre um espaço de ocupação consigo mesmo, uma prática de si, bem diversa da práxis política usual.

Contudo, numa direção diametralmente inversa, as instituições burguesas criaram formas de controle do agir humano, num espaço e tempo concretos, de modo a aumentar a produtividade dos trabalhadores, a partir de um regime disciplinar, e alimentar a máquina capitalista e estatal. A aposta de Foucault é desvincular as capacidades possíveis de serem desenvolvidas na relação consigo mesmo da intensificação das relações de poder. O "ascetismo indispensável" (FOUCAULT, 2008, p. 344) de Baudelaire contrapõe-se, nesse caso, ao regime disciplinar imposto por instituições, algo que seria, em termos marxianos, um trabalho alienado. O ascetismo do poeta serve a ele mesmo, a disciplina imposta pelas instituições maquiniza os corpos dóceis dos sujeitos e serve à empresa, ao Estado, ao capital.

Foucault se filia explicitamente às mudanças de comportamento da contracultura quando diz que nos últimos 20 anos (de 1964 a 1984) ocorreram "transformações muito precisas" em domínios parciais que são bem mais eficientes do que promessas gerais. E não se imiscui da tarefa iluminista, mesmo que reformulada, quando diz que é preciso "avançar para tão longe e tão amplamente quanto possível o trabalho infinito da liberdade" (FOUCAULT, 2008, p. 348). Ele deixa claro que a liberdade não é um conceito abstrato e vago: ela exige um trabalho constante, micrológico, assim como, aos olhos de Kant, não se concebe iluminismo senão se perguntando que tipo de restrição ele impõe.

Se se comparar sua análise das relações concretas do regime disciplinar nas instituições (fábricas, hospitais, escolas, prisões) com as estruturas de absorção da percepção da indústria cultural de Adorno e a deterioração da atenção no recente vício dos usuários em máquinas de imagem de Türcke, vê-se que os três se complementam. Evidencia-se como a totalidade desses 
diferentes modos de subtração da autonomia dificultam imensamente propostas positivas. Mas elas existem. Do mesmo modo, o mergulho nas sutilezas da forma artística de Adorno, os exercícios de retenção de Türcke e os diversos modos de ocupação consigo mesmo que Foucault estuda em diferentes momentos históricos (a estética da existência dos gregos, o cuidado de si, a escrita de si dos filósofos romanos, a hermenêutica do sujeito nos cristãos) até correlacioná-los com a modernidade de Baudelaire e a atitude de Kant, todos levantam propostas de elaboração de si que podem se contrapor aos modos de subtração da liberdade. Enquanto a sociedade moderna apresenta novas relações de poder, é possível resgatar antigas formas de exercitar capacidades individuais, reatualizando-as ou, no mínimo, sensibilizar-se com seu potencial inspirador e inventar novas, enfim, testar experimentos no mundo de hoje, resistindo aos fatores negativos de novas vivências. Tudo isso exige, como não poderia deixar de ser, muito exercício de discernimento, teórico e prático, ou seja, um amplo uso da razão crítica, não só para se tomar posição diante de questões políticas e existenciais, mas para adentrar no trabalho inesgotável em torno do próprio uso do cotidiano, algo muito maior que a mera pregação de "bons hábitos".

Essas considerações servem para mostrar o quanto a conjunção iluminista entre autonomia e uso público da razão, entre cultivo do espírito e engajamento político, extremamente influente e dominante até hoje, introduziu no sentido tanto comum quanto científico da categoria de "prática" sempre a ideia de utilidade ou de participação política, dificilmente a de ocupação consigo, elaboração de si. Na verdade, esse problema remonta à antiguidade: o sentido que os gregos atribuem à prática é geralmente utilitário ou político; a noção de ascese, isto é, atletismo espiritual, começou a ser mais amadurecida pela filosofia helênica e romana, especialmente no epicurismo e no estoicismo, e encontrou uma abordagem mais sistemática somente em Evágrio, representante dos padres do deserto que originou os princípios do monasticismo. Recentemente Agamben estudou o conceito de "forma de vida" desenvolvido ao longo de toda a Idade Média monástica (AGAMBEN, 2014, p. 11, 124-125), que foi, justamente, um período riquíssimo de desenvolvimento da "prática espiritual" (para usar o conceito de Pierre Hadot que influenciou Foucault). Quando a Renascença retoma a vida nas cidades, começa a se colocar no primeiro plano, de novo, a ideia de prática política, ainda que 
haja, ao mesmo tempo, todo o florescimento da mística especulativa e nupcial (Brautmystik), como claro desdobramento do monasticismo, até o século de ouro espanhol, de Teresa D'Ávila a João da Cruz. Foi precisamente em tempos iluministas que a mística entrou em decadência (ainda que o esoterismo tenha, a partir daí, crescido, para complicar nossas noções habituais) e a revolução francesa exigiu participação de toda a população em conflitos sociais. Daí em diante, a noção de prática espiritual foi colocada em segundo plano e em boa parte dos saberes ficou obscurecida.

Fiz um breve esquema histórico para assinalar como que a prática de si floresceu em períodos considerados pela história convencional como "menores" e como os supostos períodos mais "avançados" a esqueceram. Há lições decisivas a se tirar daí.

Se Kant se demora, em seu texto, em expor como se deve obedecer à religião, no uso privado, sendo possível questioná-la, no uso público, o problema de fundo é o quanto a religião entrava, em seu empenho tutelar, o pensamento livre dos fiéis, inclusive dos clérigos. Do final do século XIX até meados dos anos 70 imaginava-se que um dia a humanidade poderia se livrar de crenças religiosas. Dos anos 80 em diante, essa perspectiva revelou-se falsa. Continua na ordem do dia a luta contra o cerceamento da liberdade de pensar feito pelas religiões, especialmente suas tendências abertamente fundamentalistas.

Por outro lado, o pensamento laico tem se dado conta de que não basta repudiar a cultura religiosa, pois mesmo ele está impregnado de seus elementos. Foucault, por exemplo, reconheceu que o cristianismo desenvolveu formas de subjetivação específicas que não foram contempladas na crítica ateia, mas, ao mesmo tempo, preferiu louvar a prática de si da filosofia romana. Embora Agamben e outros estejam dando alguns passos, falta ainda uma releitura ateia das práticas monásticas e místicas. Em suma: há muito o que se aprender com a história da religião, estando fora dela. Se o vício em telas hoje está deteriorando a concentração, técnicas devocionais ocidentais, orientais e indígenas carregam um saber curioso a esse respeito. O domínio da espiritualidade deveria ser repensado com muito cuidado por olhos seculares, tomando, é claro, distância das falsas promessas do mercado de Nova Era. De todo o modo, a existência desse mercado aponta não somente para o escapismo, mas também para o desejo de experimentar algo mais do que a autoconservação burguesa pós-moderna, por 
incrível que pareça. Menosprezar sumariamente o legado ascético da história das religiões e mesmo o espaço aberto pelo mercado atual dela tem sido, a meu ver, um grande erro do pensamento crítico; erro que está por trás de muitos fracassos da razão emancipatória hoje.

Se, nos tempos da primeira geração da teoria crítica, a tarefa era de produzir uma autocrítica da Aufklärung, levando em consideração seu retorno ao mito, a dimensão psíquica irracional e o papel da arte, penso que, se há uma tarefa importante do pensamento crítico, hoje, é a de acrescentar a esses itens uma reavaliação da relação do modo de vida não religioso com a ascese e mística religiosa, bem como das ricas afinidades e diferenças entre elas e a arte moderna.

\section{Referências bibliográficas}

ADORNO, Teodor W. Notas de Literatura I. São Paulo: Duas Cidades; 34, 2003.

ADORNO, Theodor W. Palavras e sinais. Petrópolis: Vozes, 1995.

ADORNO, Theodor W. Kulturkritik und Gesellschaft II. Gesammelte Schriften 10.2. Frankfurt am Main: Suhrkamp, 1977.

ADORNO, Theodor W. Noten zur Literatur. Gesammelte Schriften 11. Frankfurt am Main: Suhrkamp, 1974 .

AGAMBEN, Giorgio. Altíssima pobreza: regras monásticas e formas de vida. São Paulo:

Boitempo, 2014.

BÜRGER, Peter. Teoria da vanguarda. Tradução: José Pedro Antunes. São Paulo: Cosac Naify, 2008.

FOUCAULT, Michel. Arqueologia das ciências e história dos sistemas de pensamento. Rio de Janeiro: Forense Universitária, 2008.

HUXLEY, Aldous. As portas da percepção e O céu e o inferno. Rio de Janeiro: Civilização Brasileira, 1966.

KANT, Immanuel. Textos seletos. Petrópolis: Vozes, 1974.

OTTO, Rudolf. O sagrado: os aspectos irracionais na noção do divino e sua relação com o racional. Petrópolis: Vozes, 2007.

TÜRCKE, Christoph. Hiperativos: abaixo a cultura do déficit de atenção. Rio de Janeiro: Record, 2016. 
TÜRCKE, Christoph. Hyperaktiv! Kritik der Aufmerksamkeitsdefizitkultur. München: C.H.Beck, 2012.

TÜRCKE, Christoph. Philosophie des Traums. Munchen: C.H. Beck, 2008.

' Professor Associado do Programa de Pós-Graduação em Ciência da Literatura da Faculdade de Letras - UFRJ; Bolsista de Produtividade em Pesquisa do CNPQ; Autor do livro Sublime e Violência: Ensaios sobre poesia brasileira contemporânea (Azougue, 2018) entre outros. 